\title{
AMS Review: Progress toward a world-class journal dedicated to theory development
}

\author{
Manjit S. Yadav ${ }^{1}$ \\ Received: 13 May 2019 / Accepted: 13 May 2019 / Published online: 24 May 2019 \\ (C) Academy of Marketing Science 2019
}

It has been a pleasure and a distinct honor to serve as Editor of AMS Review during these past six years. I'm very pleased that a noted marketing scholar, Steve Vargo, will be the next Editor of AMSR and continue the journal-building efforts.

In 2013, when I began transitioning into my role as Editor, AMS Review was still in its formative years. The journal had published its inaugural issue in 2011 and its unique positioning - an exclusive focus on conceptual articles aimed at theory development - was just beginning to attract the attention of marketing scholars. I would like to thank the Academy of Marketing Science and the previous AMSR Editors, Bob Peterson and Vicky Crittenden, for their foresight and efforts to launch the journal. AMSR's launch in 2011 arrived at a critically important time in the marketing discipline's evolution. While our discipline was advancing admirably on multiple fronts, scholarly trends in the marketing discipline appeared to have shifted dramatically over the past several decades. In particular, the decline of conceptual articles was continuing unabated. I had written about these troubling trends impacting knowledge development in our discipline (Yadav 2010; see also MacInnis 2011), so I was pleased when I learned about AMSR's launch. In the management discipline, Academy of Management Review (launched in 1978) had successfully established a position of considerable prominence and, more importantly, had strengthened the management discipline. Given the success and impact of $A M R$ in management, I felt that AMSR could play a similar role in marketing. Serving as Editor of AMSR over these past six years has reinforced this early perspective.

As I conclude my term as Editor, I would like to provide an overview of a number of new initiatives that were launched during the past several years. These initiatives would not have

Manjit S. Yadav

yadav@tamu.edu

1 Mays Business School, Texas A\&M University, College Station, TX 77843-4112, USA been possible without the dedicated support of many scholars who generously devoted countless hours to develop and implement them. In particular, I would like express my gratitude to the Advisory Board members (O.C. Ferrell, Hubert Gatignon, Ajay Kohli, and Debbie MacInnis) who helped brainstorm and provided valuable counsel at critically important phases of these initiatives. I also relied on an extensive network of scholars, including AMSR's Editorial Review Board members, who supported the long-term mission of AMSR. Finally, a special word of thanks to Len Berry and Rajan Varadarajan, my colleagues at Texas A\&M University, who generously shared their time and ideas. To all these friends and supporters of AMSR's mission, Laurie Marshall (AMSR's Managing Editor), and Nick Philipson (at Springer), my heart-felt thanks.

\section{New initiatives to enhance AMSR's visibility}

During my term as Editor, the overarching objective has been to establish a strong foundation for AMSR's future growth by enhancing its visibility in the marketing discipline. My longterm aspiration for the journal is to see it evolve into a worldclass journal that, in conjunction with the efforts of other leading journals, significantly advances conceptual work in marketing aimed at theory development. In earlier editorials (Yadav 2014, 2017), I have discussed my perspective on these and related issues. Building on the ideas and views presented in these editorials, we launched a number of initiatives to enhance the long-term impact of AMSR. Below, I will provide a broad overview of these initiatives.

New series of articles by award-winning authors In 2014, we started a new series of articles authored by winners of the influential Sheth Foundation/Journal of Marketing Award. In occasional issues of AMSR, we have featured one of these articles as the lead article - accompanied by value-added commentaries that provide context. Marketing scholars featured in 
this series include: Philip Kotler, Richard Bagozzi, Ajay Kohli, Bernie Jaworski, Sidney Levy, Shelby Hunt, Kevin Keller, Neil Morgan, Sundar Bharadwaj, Alice Tybout, Debbie John, Rajan Varadarajan, Bobby Calder, Jerry Zaltman, Adel El-Ansari and others. Articles in this series (e.g., Keller 2016; Jaworski and Kohli 2017) provide a unique retrospective and forward-looking discussion of substantive and conceptual issues that we don't see very often in our journals. In addition to such articles that were focused on specific substantive and conceptual issue in marketing, this new series of invited articles also provided an opportunity to feature the work of influential thinkers in our field on topics that applied more broadly to theory development endeavors (see, e.g., Zaltman's 2016 article on imagination).

AMS Review's Theory Forum In 2014, AMS Review launched the inaugural Theory Forum at the annual AMS Conference in Indianapolis. O.C. Ferrell and I served as co-chairs of this event. The long-term strategic purpose of the annual Theory Forum is to facilitate an annual gathering of marketing scholars who are interested in conceptual work aimed at theory development. The Theory Forum's strategic purpose is thus closely aligned with AMSR's mission. Specifically, the Theory Forum has the following objectives:

- Critically assess the state of knowledge development in marketing, with special emphasis on theoretical progress.

- Identify significant theory development gaps in various substantive domains and advance proposals for addressing these gaps.

- Discuss specific strategies and tools that marketing scholars can utilize for enhancing theory-building efforts in their research programs.

- Strengthen institutional factors (e.g., journals and doctoral programs) to reinvigorate theory development in the marketing discipline.

The inaugural event in Indianapolis was received enthusiastically by marketing scholars. We have now successfully organized five forums at the Annual AMS Conference and the sixth event will be held this year. Many leading scholars have presented at these forums: Shelby Hunt, Ajay Kohli, Dave Stewart, Bill Wilkie, Kent Monroe, Lisa Scheer, Peter Golder, Rajan Varadarajan, Linda Price, John Lynch, Terry Clark, Ruth Bolton, David Griffith, and others. The Theory Forum has allowed AMSR to create a community of leading marketing scholars who are supportive of its long-term mission. In recent years, the forum has been held in conjunction with the AMS Doctoral Consortium's activities. As a result, AMSR is able to add value to the consortium activities and connect with a new generation of marketing scholars who are interested in issues related to theory development.
AMS Review/Sheth Foundation doctoral competition for conceptual articles The idea for this competition emerged quite serendipitously in two separate meetings. Ruth Bolton, during an informal conversation after an Editorial Review Board meeting in Orlando (2016), suggested that AMSR could play an important role in connecting with doctoral students and encouraging them to get more involved in research efforts aimed at theory development. A few months later, I was attending the AMA Doctoral Consortium at the University of Notre Dame and had a delightful conversation with Jag Sheth during a dinner event. Jag shared stories from the early years of his career, noting the significant impact of John Howard on his development as a scholar. John Howard challenged Jag's thinking, but also gave him substantial freedom to propose new ideas. This mix of intellectual challenge and freedom, especially during the early years of his career, empowered Jag to embark on an ambitious theory development effort with John. This collaboration eventually led to the publication of their seminal book The Theory of Buyer Behavior (Howard and Sheth 1969). That dinner conversation with Jag had a significant impact on me and I became increasingly convinced that AMSR should make an effort to connect with doctoral students.

A few weeks after the dinner conversation at Notre Dame, I wrote to Jag about the possibility of developing a new annual competition that would encourage doctoral students to develop research efforts aimed at theory development. Based on Jag's suggestions, we developed a formal proposal for consideration by the Sheth Foundation. The Sheth Foundation's Board Members supported the proposal that Barry Babin, O.C. Ferrell, and I presented and the inaugural AMS Review/Sheth Foundation Doctoral Competition for Conceptual Articles was launched in 2017. Ajay Kohli and I served as Co-Chairs of the inaugural competition. Since then, the annual competition has evolved with the dedicated efforts of a number of scholars who have contributed as Co-Chairs (Jagdip Singh, Jelena Spanjol, Pierre Berthon, and Kristina Heinonen).

The competition has three key objectives: (a) Encourage doctoral students to identify and publish impactful conceptual ideas in their research; (b) Help doctoral students connect with leading marketing scholars, and obtain feedback to enhance their conceptual contribution; and (c) Advance theory development in the marketing discipline. Lead authors of the winning proposals receive a monetary award (to help with travel expenses) and present at the AMS Conference in a Special Session. Winners are also encouraged to submit full articles based on their winning entry to AMSR. These articles go through a formal review process. I'm very pleased that a few of the winning entries have successfully gone through the review process and have been published in AMSR. I consider this as a very promising sign that the competition is achieving its core objective of encouraging doctoral students to add conceptual papers to their portfolio of research projects that they develop during the doctoral program. By developing such 
papers early in their careers, there is a greater likelihood that they will continue conceptual research endeavors as their career advances. Over the long term, such endeavors will strengthen the marketing discipline. I am pleased that AMSR, through this competition, is facilitating these efforts.

New section - Theory + Practice During 2017, I worked with AMSR's Advisory Board to develop a new section: Theory + Practice. The goal is to explore, in a rigorous manner, the connections between practice and theory development. We were very fortunate to attract a leading marketing scholar, Bernie Jaworski, to serve as the inaugural Section Editor in the June 2018 issue. In an Editorial that appeared in that issue, Jaworski $(2018$, p. 1) noted that that this new initiative "is designed to enhance the ability, time, and motivation of marketing academics to hear the voice of the senior executive and translate the voice into a researchable set of issues." As this section evolves over time, I'm sure new ideas will emerge about how such perspectives from the world of practice can inform impactful theory development efforts. By creating a forum for such exchanges, AMSR has the potential to make a valuable contribution to the marketing discipline.

Special issues and sections In 2017, AMSR published a Special Issue ("A Marketing Perspective on Business Models"). A global team of leading scholars served as CoEditors: Hubert Gatignon, Xavier Lecocq, Koen Pauwels, and Alina Sorescu. This Special Issue allowed us to explore theory development opportunities related to business models in a broad spectrum of areas such as marketing ecosystems, big data, emerging markets, crowdsourcing, and several other promising domains (see Gatignon et al. 2017).

I am also very excited about our first Special Section ("Innovation in Healthcare Service") that is featured in this issue of AMSR. In this Special Section, Len Berry has assembled articles from an outstanding group of scholars and medical professionals. The over-arching theme of these articles is "patient-centered healthcare" (see Berry 2019). This thematic focus on the patient (customer) showcases very effectively how theories, frameworks, and other conceptual elements from the marketing discipline can be harnessed productively to understand a range of complex issues in healthcare - controlling spiraling costs, developing innovative new partnerships, shared decision making, and others. The Theory + Practice articles in this issue are also focused on issues pertaining to healthcare.

During my term as Editor, we have been quite selective in terms of Special Issues and Sections. This deliberative approach, during these early years of AMSR, has allowed us to focus more closely on creating increased levels of consistency in terms of the rigor of our review process. We have also gained considerable experience in working with other scholars to help advance AMSR's editorial mission. As the journal matures, I envision that AMSR will build on this foundation to explore an expanded range of opportunities pertaining to Special Issues and Sections.

\section{Looking forward: An upward trajectory}

AMS Review continues to make excellent progress on several fronts. However, as we know, the task of building a worldclass journal takes considerable time and effort and sustained investments from a community of scholars. Although much remains to be done, there are a number of encouraging signs that the global community of marketing scholars sees considerable value in AMSR and how it can strengthen knowledge development in the discipline. Consider, for instance, trends related to the number of AMSR articles that have been downloaded annually in recent years (see Fig. 1). Article downloads in each year were as follows: 8008 (2014); 7861 (2015); 20,382 (2016); 29,274 (2017); and 41,401 (2018). As Fig. 1 shows, this increase is spread out evenly across the
Fig. 1 Full-Text downloads of AMS Review articles from SpringerLink (2014-2018). Source: COUNTER Reporting/ Business Warehouse

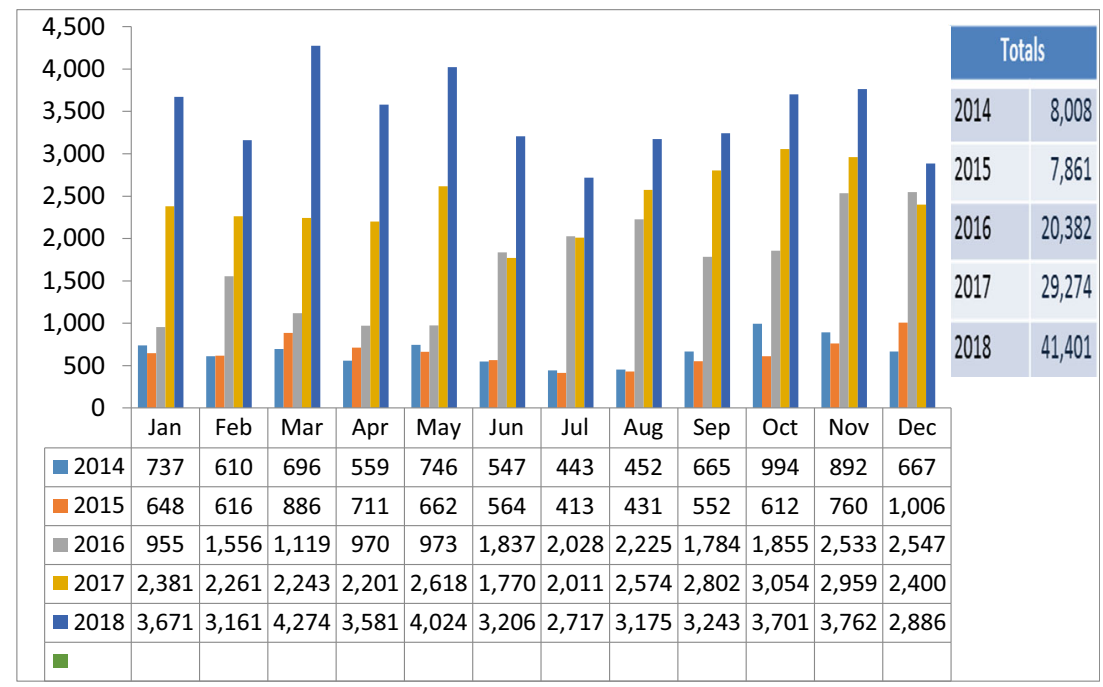


months each year, which suggests sustained interest in content produced by AMSR. Overall, the approximately five-fold increase in article downloads from 2014 to 2018 indicates that the journal-building efforts described above are beginning to connect with marketing scholars.

Over the next few years, as AMSR expands its cumulative body of articles published, and works with Clarivate Analytics to start measuring its Impact Factor as part of the Social Sciences Citation Index (SSCI), there will be additional metrics available that can be used to guide the journal-building efforts. These metrics will also facilitate AMSR's on-going efforts to be featured in an expanded set of databases that index/abstract academic journals. With a focus on quality, we are currently publishing about 20 articles each year. As the journal matures, this number is likely to trend upward over the years. More generally, going beyond the metrics, what really matters during these formative years of AMSR is that it stay focused on creating a vibrant, sustainable community of marketing scholars who are passionate about impactful ideas and theory development in the discipline.

Looking ahead, AMS Review is well positioned to keep advancing toward its long-term aspiration - to be a worldclass journal that is focused exclusively on conceptual work aimed at theory development in marketing. In recent years, leading scholars from around the world have stepped up to support the journal's mission. During my term as Editor, I have worked closely with these scholars and I'm grateful for the energy and ideas they contributed to help AMSR move forward. These interactions have also shown that there are many highly accomplished and dedicated marketing scholars around the world who would like see more impactful conceptual work and theory development in our discipline. I'm confident that AMSR will continue growing this community of scholars so that our discipline remains vibrant and strengthens its position in the family of other disciplines in the social sciences. I hope you will consider joining AMS Review on this journey so that, collectively, we can further enhance marketing knowledge.

\section{References}

Berry, L. L. (2019). Patient-centered innovation in healthcare. AMS Review, 9(1-2) this issue.

Gatignon, H., Lecocq, X., Pauwels, K., \& Sorescu, A. (2017). A marketing perspective on business models. AMS Review, 7(3-4), 85-89.

Howard, J. A., \& Sheth, J. N. (1969). The theory of buyer behavior. New York: Wiley.

Jaworski, B. J. (2018). Introducing the Theory + Practice section. AMS Review, 8(1-2), 1-4.

Jaworski, B. J., \& Kohli, A. (2017). Conducting field-based, discoveryoriented research: Lessons from our market-orientation experience. AMS Review, 7(1-2), 4-12.

Keller, K. L. (2016). Reflections on customer-based brand equity: Perspectives, progress, and priorities. AMS Review, 6(1-2), 1-16.

MacInnis, D. J. (2011). A framework for conceptual contributions in marketing. Journal of Marketing, 75(July), 136-154.

Yadav, M. S. (2010). The decline of conceptual articles and implications for knowledge development. Journal of Marketing, 74(1), 1-20.

Yadav, M. S. (2014). Enhancing theory development in marketing. AMS Review, 4(June), 1-4.

Yadav, M. S. (2017). Disciplinary memory and theory development. AMS Review, 7(1-2), 1-3.

Zaltman, G. (2016). Marketing's forthcoming age of imagination. AMS Review, 6(3-4), 99-115.

Publisher's note Springer Nature remains neutral with regard to jurisdictional claims in published maps and institutional affiliations. 